\title{
A neglected case of Sacrococcygeal teratoma in a neonate
}

\author{
Monojit Mondal', Biswajit Biswas ${ }^{2}$, Atanu Roy², Abhijit Ari ${ }^{3}$, Kaustav Nayek ${ }^{4}$, Asok Kumar Datta ${ }^{5}$, \\ Kriti Sundar Rana', Nayan Banerji ${ }^{1}$
}

${ }^{1}$ Resident, Department of Pediatric Medicine, Burdwan Medical College and Hospital, Burdwan, India, ${ }^{2}$ Assistant Professor, Department of Pediatric Medicine, Burdwan Medical College and Hospital, Burdwan, India, ${ }^{3}$ RMO cum clinical tutor, Department of Pediatric Medicine, Burdwan Medical College and Hospital, Burdwan, India, ${ }^{4}$ Professor, Department of Pediatric Medicine, Burdwan Medical College and Hospital, Burdwan, India, ${ }^{5}$ Professor and Head, Department of Pediatric Medicine, Burdwan Medical College and Hospital, Burdwan, India

\section{A B S T R A C T}

Sacrococcygeal teratoma (SCT), although rare, is the most common congenital neoplasm in neonates. A mass in the sacrococcygeal region at the time of birth is the usual presentation. Routine antenatal abdominal ultrasound of mother can detect almost all the cases. The prognosis is favorable when diagnosis is done antenatally and proper management is instituted soon after the baby is born. Presented herein a 2 days old neonate with a neglected SCT who died unfortunately due to massive bleeding from the tumor. A brief review of the literature has been presented to make everyone aware of the condition so that future recurrence of such sad events may be avoided.

Key words: Teratoma, Sacrococcygeal, Massive bleeding

\section{INTRODUCTION}

Teratomas are embryonal neoplasms that contain tissues from all three germ cell layers. Sacrococcygeal location is most common, particularly in infancy and childhood but it may involve pineal region, retroperitoneum, mediastinum, testes and ovary also. SCT has an incidence of approximately 1 in 35,000 to 1 in 40,000 live births. Female to male ratio is $4: 1 .^{1,2}$

They may be benign (mature) or malignant (immature, composed of embryonic elements). Mature teratomas are more common in neonates and older children. ${ }^{3}$ Antenatal diagnosis is very crucial to prevent fetal and neonatal death. Perinatal and neonatal mortality and morbidity increases when the tumors are associated with complications like malignant invasion, hemorrhage into the tumor, high output cardiac failure, obstruction of the umbilical flow, non-immune fetal hydrops and bladder outlet obstruction, and in cases of preterm birth. ${ }^{4}$ Early surgical intervention can save the life in most of the cases. ${ }^{5}$

\section{CASE REPORT}

A $3.5 \mathrm{~kg}$ girl neonate born out of a non-consanguineous marriage to a gravida 4 para 3 women of 32 years of age presented on the $2^{\text {nd }}$ day with a large mass in the sacrococcygeal region. The mother belonged to a very poor socio-economic family and did not have any kind of antenatal check-ups whatsoever. No antenatal ultrasound was performed. Baby was delivered vaginally at 35 weeks of gestation at home by traditional birth attendants and the mass on her back was completely overlooked with the hope that it may regress with time. Somehow, the baby was referred to our hospital due to active bleeding from the mass. On presentation, general activities of the baby were depressed. Her heart rate and respiratory rate were $148 / \mathrm{min}$ and $37 / \mathrm{min}$ respectively. Temperature recorded was $36.2^{\circ} \mathrm{C}$. Capillary refill time was 4 seconds and anterior fontanel was depressed. A $20 \mathrm{~cm} \times 14 \mathrm{~cm}$ mass was found in the sacrococcygeal region with a lobulated surface and variable consistency. On the surface of the mass, there was dilated veins. Fresh bleeding from the 
mass was noticeable. The anus was displaced anteriorly (Figure 1). Examination of other systems were noncontributory. Ultrasound examination of the mass showed mixed echogenicity pattern with large anechoic cystic areas and scattered small hyper echoic areas. Vascular supply was good. No intrapelvic extension was noted. The tumor was classified as SCT type I according to The American Academy of Pediatrics Surgical Section (AAPSS) classification. Considering the unstable clinical condition of the baby, conservative treatment with moist oxygen, intravenous fluid, broad spectrum antibiotics were started immediately. Purified packed red blood cells and fresh frozen plasma was transfused. The baby died within 3 hours of admission due to torrential bleeding from the tumor despite aggressive resuscitation efforts.

\section{DISCUSSION}

SCT is the most common teratoma presenting in the neonatal period. Although their embryonic origin is still unclear, they are thought to arise early in gestation (at around late second or early third week) from the totipotent cells of the primitive knot, a remnant of the primitive streak in the coccygeal region. ${ }^{6}$ According to the American Academy of Pediatrics surgical section (AAPSS) classification, ${ }^{7}$ SCTs are graded as follows: Type I (47\%): Predominantly external tumor with minimal pre-sacral component; type II (35\%): Present externally but with significant intrapelvic extension; type III (8\%): Apparent externally but predominantly a pelvic mass extending into the abdomen, and type IV (10\%): Pre-sacral with no external presentation. ${ }^{7}$ Our case belonged to SCT type I according to this classification system.

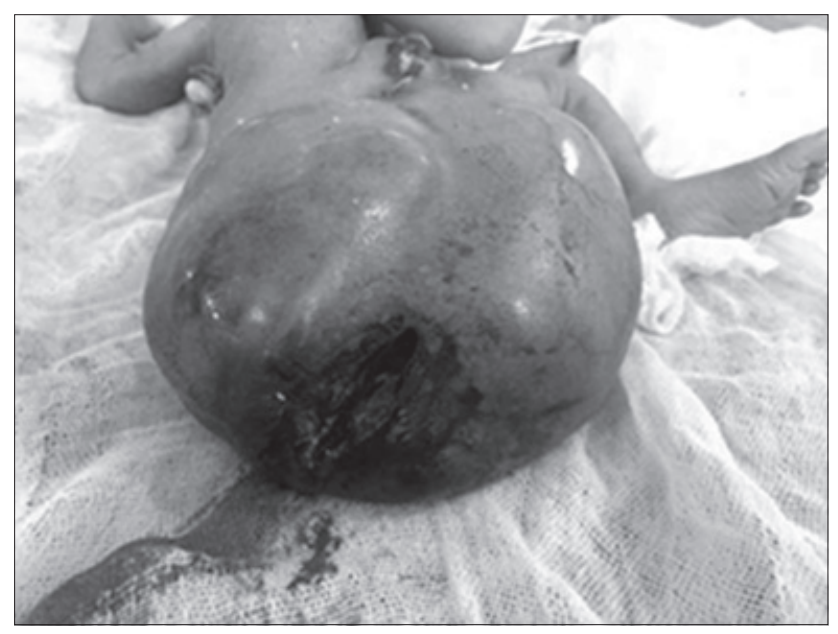

Figure 1: Showing large $20 \times 14 \mathrm{~cm}$ size SCT with lobulated surface, dilated vessels on the surface and bleeding from the tumor
SCT can be both solid and cystic in nature. It may be malignant from $10 \%$ in the neonatal period, and up to $50 \%$ if excision is delayed. A routine antenatal ultrasound of the abdomen performed at second trimester can identify the mass and associated polyhydramnios. A large tumor may cause dystocia for which caesarean section may be required. Alpha-fetoprotein is a useful tumor marker. Apart from the supportive treatment, the standard specific treatment includes en-bloc excision of the mass with removal of coccyx within the first few days of life. Risk of bleeding is more in immature or vascular tumors. When the tumor is more advanced or non-resectable, chemotherapy is the feasible option. ${ }^{2,8}$

Recurrence can occur in cases of incomplete resection of the tumor, incomplete enbloc removal of the coccyx along with the tumor, tumor spillage, and failure to detect malignant components within the tumor.?

\section{CONCLUSION}

SCTs in the neonatal period and early childhood are mostly of mature type and are benign in nature. Diagnosis is very easy in the antenatal period by abdominal ultrasound. Most of the cases have a favorable outcome with timely and appropriate surgical intervention. It is our responsibility that all pregnancies should have regular antenatal check-ups and at least one ultrasound of mother be performed to avoid this kind of mishap as happened in the present case.

\section{REFERENCES}

1. Afolabi IR. Sacrococcygeal teratoma: A case report and a review of literature. Pac Health Dialog 2003; 10:57-61.

2. Chisholm CA, Heider AL, Kuller JA, von Allmen D, McMahon MJ and Chescheir NC. Am J Perinatol 1999;16(1):47-50.

3. Keslar PJ, Buck JL and Suarez ES. Germ cell tumors of the sacrococcygeal region: Radiologic-pathologic correlation. Radio graphics 1994; 14:607-622.

4. Holterman AX, Filiatrault D, Lallier M and Youssef S: The natural history of sacrococcygeal teratomas diagnosed through routine obstetric sonogram: a single institution experience. J Pediatr Surg 1998; 33(6):899-903.

5. Kum CK, Wong YC and Prabhakaran K. Management of fetal sacroccocygeal teratoma. Ann Acad Med Singapore 1993; 22:377-380.

6. Moazam F and Talbert JL. Congenital anorectal malformations: Harbingers of sacrococcygeal teratomas. Arch Surg 1985; 120:856-859.

7. Altman RP, Randolph JG and Lilly JR. Sacrococcygeal teratoma: American Academy of Pediatrics Surgical Section Survey-1973. J Pediatr Surg1974; 9:389-398.

8. Schmidt B, Haberlik A, Uray E, Ratschek M, Lackner $\mathrm{H}$ and Hollwarth ME. Sacrococcygeal teratoma: Clinical course and 
prognosis with a special view to long-term functional results. Pediatr Surg Int 1999; 15:573-576.

9. De Backer A, Madern GC, Hakvoort-Cammel FG, Haentjens P,
Oosterhuis JW and HazebroekFW. Study of the factors associated with recurrence in children with sacrococcygeal teratoma. J Pediatr Surg 2006; 41(1):173-181.

Authors Contribution:

MM, BB - Drafting the manuscript and review of literature; AR , AA - Editing and manuscript revision; KN, AKD - Editing, review of literature and overall supervision; KSR, NB - Clinical data and photograph collection, work up of the case.

Source of Support: Nil, Conflict of Interest: None declared. 